\title{
Individuación y conatus. \\ Acerca de la existencia inter-afectiva de los modos singulares en la filosofía spinoziana
}

\author{
Individuation and conatus. About the inter-affective existence of the \\ singular modes in spinozian philosophy
}

Por: Jabase, Ana Leila*

Universidad Nacional de Córdoba

Córdoba, Argentina

Email: a.leila.jabase@gmail.com

Fecha de recepción: 6/04/2019

Fecha de aprobación: 10/05/2020

DOI: $\underline{10.30972 / n v t .1614344}$

\section{Resumen}

En el presente artículo, tratamos lo que consideramos un problema central de la filosofía spinoziana: la individuación y sus procesos de generación. Atendemos a la relación entre individuo y conatus, donde este último no es más que la expresión de la esencia actual de aquel, que es a la vez una fuerza de perseverancia, una potencia, un cuerpo. Igualmente, analizamos tanto la constitución inter-afectiva de los cuerpos, así como su propia unidad o integridad, es decir, aquello que lo configura y singulariza como el individuo que es. Intentaremos mostrar allí no solo la singularidad filosófica del pensamiento spinoziano, sino también su actualidad, al comprender al cuerpo en tanto que constituido por una complejidad material marcadamente relacional, como un complejo de imágenes internas y externas a otros cuerpos que lo circundan. En ese

\footnotetext{
* Miembro del Grupo de Estudios Spinozistas de Córdoba. Miembro del grupo de investigación Spinozismo Contemporáneo. Ontología, Realismo y Democracia (SECyT-UNC). Miembro del grupo de investigación "La sabiduría del idiota en el pensamiento de Nicolás de Cusa (1401-1464) y su proyección en la Filosofía Moderna" (CiFFyH-UNC). Docente Adscripta en la cátedra de Filosofía Moderna I de la Universidad Nacional de Córdoba. Becaria doctoral SECYT-UNC.
} 
sentido, se verá cómo la noción de individuo en Spinoza se encuentra enlazada a los conceptos de potencia y esencia actual (conatus), la cual es sucesivamente ampliada por composiciones y descomposiciones infinitas que dejan su trazo, afectando y siendo afectadas entre sí. Asimismo, nos ocupamos de la cuestión de cómo el cuerpo ha de ser comprendido en la filosofía de Spinoza como una imagen, que se construye por vestigios y marcas, y donde el atributo extenso mismo también es una trama, es un tejido de relaciones, es una red de comunicaciones que transmite movimientos y velocidades. A partir de allí se verá, pues, de qué manera el cuerpo reviste una forma, la cual subsiste a las diversas transformaciones que porta, constituyéndose -por eso mismo- no solo como una forma ética, sino también como un cuerpo político, o sea, un nuevo individuo.

Palabras clave: Individuación, conatus, afectos, cuerpo, relaciones.

\section{Abstract}

In this article, we deal with what we consider a central problem of spinozian philosophy: the individuation and the processes of its generation. We attend to the relationship between individual and conatus, where the latter is nothing more than the expression of the actual essence of the latter, which is at the same time a force of perseverance, a potency, a body. Likewise, we analyze both the inter-affective constitution of bodies, as well as their own unity or integrity, that is, what configures and singles them out as the individual they are. We will try to show there not only the philosophical singularity of spinozian thought, but also its current interest, when understanding the body as constituted by a markedly relational material complexity, as a complex of internal and external images to other bodies that surrounds it. In this sense, it will be seen how the notion of individual in Spinoza is linked to the concepts of power and actual essence (conatus), which is successively expanded by infinite compositions and decompositions that leave their trace, affecting and being affected each other. Likewise, we deal with the question of how the body is to be understood in Spinoza's philosophy as an image, which is built by vestiges and marks, and where the 
Individuación y conatus.

Acerca de la existencia inter-afectiva de los modos singulares en la filosofía spinoziana.

extensive attribute itself is also a plot, is a fabric of relationships, is a communication network that transmits movements and speeds. From there, it will be seen, then, how the body has a form, which subsists to the various transformations it carries out, constituting itself - for this very reason - not only as an ethical form, but also as a political body, that is, a new individual.

Keywords: Individuation, conatus, affects, body, relations.

\section{Cómo citar este artículo:}

APA: Jabase, A. L. (2020). Individuación y conatus. Acerca de la existencia inter-afectiva de los modos singulares en la filosofía spinoziana. Nuevo Itinerario, 16 (1), 22-50. Recuperado de: (agregar dirección web)

\section{Introducción: Spinoza actual}

"La prudencia es para los contemporáneos" (Meschonic, 2015, p. 3), puesto que es entre ellos que se vive, ya sea unidos o separados. Así comienza escribiendo Henri Meschonnic en su obra Spinoza poema del pensamiento; es por ello -agrega- que el lema de Spinoza es Caute, pues el pensamiento, en el sentido de la invención de algo, tiene un tiempo distinto al nuestro (Meschonic, 2015). Implica un aire nuevo que ventila el tufo enrarecido de lo contemporáneo, del status quo, de lo dado. Sin duda hay en la historia sobradas muestras de la vinculación entre el pensar y el correr peligro, entre tener ideas y asumir riegos; riesgos que incluso incumben a la propia vida. Spinoza sabía bien de qué se trataba, como puede constatarse por uno de sus biógrafos: "Por más hombre de bien que haya sido, no pudo vivir seguro" (Domínguez, $1995,168)^{1}$. En efecto, se dice que la comunidad judía de Ámsterdam -consciente de la peligrosidad de sus ideas- le ofreció tolerarlo siempre que aceptara acomodarse

\footnotetext{
${ }^{1}$ Se trata de la biografía La vie de Monsieur Benoit de Spinosa, redactada por Jean Maximilien Lucas en 1719.
} 
exteriormente al ceremonial, y que hasta le ofrecieron una pensión anual, pero que él no habría aceptado tal hipocresía. Asimismo, sumado a un supuesto ataque que habría sufrido a la salida de un teatro en el que un judío le dio traidoramente una puñalada (Bayle, 2010), terminó resultando en su ruptura definitiva con la comunidad a la que había pertenecido, siendo excomulgado en 1656. En el acta de aquel "célebre" momento -la cual aún hoy se conserva- pueden leerse referencias a la supuesta existencia de "horrendas herejías que practicaba y enseñaba" así como de "los actos monstruosos que cometió" (Domínguez, 1995, p. 186). Sobre ello cabe preguntarnos por qué alguien cuyo lema es la cautela y que eligió vivir la mayor parte de su vida alejado del escándalo fue objeto de tan rabiosa personificación. Hay quienes alegan que Spinoza no fue precisamente prudente al negar, por ejemplo, la autenticidad e inspiración divina de los textos bíblicos ${ }^{2}$; otros como Freudenthal (1988), ven en la máxima Caute una regla de desconfianza. Sin embargo, aunque es cierto que Spinoza confiaba ante todo en su círculo de amigos y actuaba en general con recelo respecto de aquellos que no conocía -y así lo hará inicialmente con Leibniz- es poco probable, como lo hace notar Chantal Jaquet, que haya elegido como lema un afecto pasional triste. La desconfianza es una forma de miedo e implica por consiguiente una disminución de la propia perfección: no podría constituir un lema meditado (Jaquet, 2008).

Ahora bien, a propósito de esta relación entre el individuo y los otros, entre el sujeto y las comunidades posibles, entre la desconfianza, la cautela y la amistad, nos interesa pensar aquí la problemática que emerge acerca de la constitución interafectiva del individuo singular. Creemos que allí es posible encontrar la actualidad de una filosofía que se expresa como una vena de pensamiento contemporáneo, en la medida en que nos permite echar luz sobre la forma en la que se construyen los vínculos, tanto en la búsqueda de lo común como en el trazado de los límites respecto de aquello que nos es extraño, que desconocemos, o que nos es simplemente externo.

Sin duda, no es Spinoza el único filósofo de envergadura que le haya dedicado un lugar al problema del individuo y de las condiciones o procesos de su generación.

\footnotetext{
${ }^{2}$ Zac, S. (1995). pp. 228-229. Strauss, L. (1973). p. 182.
} 
Individuación y conatus.

Acerca de la existencia inter-afectiva de los modos singulares en la filosofía spinoziana.

Antes bien, es posible encontrar otros conceptos de individuación en la filosofía moderna, como el caso más claro del mencionado Leibniz, pero también lo encontramos un poco antes en el mismo Descartes, aunque su teorización termine siendo altamente problemática. En cuanto a los más contemporáneos, por su parte, cabe mencionar sin duda a Marx (1994), para quien la esencia humana no es algo abstracto e inmanente a cada individuo sino que es, en su realidad, el conjunto de las relaciones sociales; o Freud, para quien el inconsciente no es ni una "facultad" individual ni un sistema "colectivo" de arquetipos ${ }^{3}$. Sin embargo, tal vez el caso más paradigmático sea el de Simondon (2009), quien elabora el concepto mismo de lo "transindividual" en su libro L'individuation psychique et collective. ${ }^{4}$

Ahora bien, dado que el carácter individual y singular de toda existencia supone indudablemente la pregunta por su unidad o integridad, en el contexto spinozista ello incumbe directamente al problema del cuerpo, por lo que será un concepto que guiará el desarrollo de este artículo. Allí radica una parte su singularidad filosófica, al comprender al cuerpo en tanto que constituido por una complejidad material marcadamente relacional, como un complejo de imágenes internas y externas a otros cuerpos que lo circundan. $Y$ es en este contexto, que el conatus mismo emerge como el principio propiamente «individuante». En ese sentido, la noción de individuo en Spinoza se encuentra enlazada a los conceptos de potencia y esencia actual, la cual es sucesivamente ampliada por composiciones y descomposiciones infinitas que dejan su trazo, afectando y siendo afectadas entre sí. A partir de allí, emerge la cuestión acerca de cómo el cuerpo ha de ser comprendido en la filosofía de Spinoza como una imagen, que se construye por sus vestigios y sus marcas, y donde el atributo extenso mismo también es una trama, un tejido de relaciones, una red de comunicaciones que transmite movimientos y velocidades. A partir de allí se verá, pues, de qué manera el cuerpo reviste una forma, la cual subsiste a las diversas transformaciones que porta, constituyéndose -por eso mismo- como una forma ética y política que implica ante todo una serie de hábitos. Tanto en el sentido de ciertas prácticas que repetimos,

\footnotetext{
${ }^{3}$ Más precisamente, es Lacan quien, en su famoso "Discurso de Roma" (1953), se sirve del concepto de transindividual para describir el inconsciente freudiano (Lacan, 2003).

${ }^{4}$ Igualmente, el sentido y el lugar central que Simondon le otorga a la individuación al interior de su propia teoría no se asemeja a ninguno de los autores antes mencionados.
} 
como también «hábito» en el sentido de un ropaje, un revestimiento, un tipo de sensibilidad o afectividad, que es siempre singular en cada modo, en cada conatus.

\section{La parte y el todo: aproximaciones al problema de la individuación}

Podría decirse que el problema de la individuación contiene, ante todo, la pregunta por las "cosas". Es decir, qué hace que algo sea eso que es y no otra cosa, cuáles son los límites que lo circunscriben, cuál el concepto que lo expresa. Al mismo tiempo, en términos spinozianos, hablar de la individualidad no es más que referirse a la forma misma de la existencia actual, y hablar de individuos es hablar siempre de compuestos, de relaciones entre partes. Los llamados cuerpos simplísimos (corpora simlicissima) que menciona Spinoza brevemente en la «Pequeña Física» de la segunda parte de la Ética, no son simplísimos por no poseer partes, sino que consisten en expresiones mínimas de potencia cuyas maneras de afectar y de ser afectados por otros modos son cercanas al cero. En palabras de Jaquet (2005), "son llamados de ese modo porque poseen pocas aptitudes y se definen por un mínimo de propiedades comunes y un mínimo de características distintivas" (p. 224). ${ }^{5}$ De forma que no hay partículas discretas o átomos últimos de la realidad, sino modificaciones de infinitos atributos que expresan una única substancia.

Por otra parte, la temática acerca de los átomos no es ajena en absoluto a Spinoza, sino que se trata de una discusión común a todos los pensadores de la época, inscripta a su vez en el marco más general de la naturaleza misma de la materia, en la que se ven interpelados los principales exponentes de la filosofía del siglo diecisiete. Las influencias epicureístas estaban a la orden del día en una época en la que la explicación mecanicista y cartesiana del universo era la dominante. Spinoza se refiere a ello en la conocida carta a Hugo Boxel, donde muestra cierta estima hacia los atomistas y defensores de los átomos -en detrimento de Platón y Aristóteles-, a propósito de una discusión sobre la existencia y naturaleza de los espectros y los fantasmas (Spinoza, 2007). ${ }^{6}$ Si bien Spinoza no comparte la tesis de la existencia de los

\footnotetext{
${ }^{5}$ Todas las traducciones del francés son de mi autoría.

${ }^{6}$ Allí, Spinoza (2007) expresa: “No pesa mucho sobre mí la autoridad de Platón, Aristóteles y Sócrates. Me habría sorprendido, si usted hubiese citado a Epicuro, a Demócrito, a Lucrecio o a alguno de los
} 
Individuación y conatus.

Acerca de la existencia inter-afectiva de los modos singulares en la filosofía spinoziana.

átomos, ello no le impide reconocer cierta simpatía hacia sus exponentes más clásicos a la vez que tomar distancia de toda suscripción a una forma absoluta y abstracta de la "esencia" de las cosas, de la cual todos los individuos participarían. ${ }^{7}$ Tampoco tienen lugar las explicaciones que oponen los atributos esenciales a los accidentales, sino que todos los predicados son constitutivos de la esencia actual de las cosas.

Ahora bien, tratándose de procesos de individuación, resulta decisivo determinar hasta qué punto puede hablarse de propiedades intrínsecas o extrínsecas, así como de interioridad o exterioridad, en referencia a los modos. Sobre todo analizando la cuestión desde el plano ontológico, donde Spinoza presenta una realidad inmanente en la que no hay un afuera de la substancia, ni exterioridad en el nivel de la naturaleza naturante que condicione sus operaciones, tal como sí ocurre en la naturaleza naturada, es decir, en el marco de las determinaciones modales, ya sean infinitas o inscriptas en la duración.

La proposición "Dios es causa inmanente, pero no transitiva, de todas las cosas" (Spinoza, 2009, p. 73), ${ }^{8}$ tal vez sea una de las más emblemáticas de la Ética y del corpus spinoziano en general, aunque la demostración que Spinoza realiza de la misma sea considerablemente breve. La misma se resume en explicar que todo lo que es, es en Dios y debe concebirse por Dios, que es causa de todas las cosas, según es axiomáticamente deducido de proposiciones precedentes. Pese a ello, junto con el lema Deus sive natura, sus consecuencias tanto metafísicas como éticas y políticas se

atomistas o defensores de los átomos; pues no ha de sorprendernos que aquellos que inventaron las Cualidades ocultas, las Especies intencionales, las Formas sustanciales y otras mil necedades, hayan fraguado los Espectros y Fantasmas y hayan creído a las viejezuelas para menoscabar la autoridad de Demócrito, de cuya buena fama estaban tan envidiosos" (pp.222-223).

En adelante, siguiendo la manera usual de citación de las obras de Spinoza, usaremos las siguientes iniciales de sus obras: KV (Tratado Breve); TIE (Tratado de la reforma del entendimiento); CM (Pensamientos metafísicos); E (Ética); TTP (Tratado teológico-político); TP (Tratado político); Ep (Epistolario). A: Axioma;C: Corolario; Cap.: Capítulo; D: Definición; L: Lema; P: Proposición; Post.: Postulado; Pref.: Prefacio; Sc: Escolio. Las Partes se citarán con números romanos.

${ }^{7}$ A este respecto, es interesante el hecho de que su propia filosofía haya sido muchas veces presentada como una forma renovada y moderna del epicureísmo, expresada en modo geométrico. Como es sabido, ello le valió la redacción de varias refutaciones de su sistema, siendo algunas de las más célebres la de Issac Janquelot y la de François Fénelon. Ver: Lagrée, J. (1994). Spinoza "athée \& épicurien», Archives de philosophie 57(3) 541-558.

${ }^{8}$ EIP18. Particularmente, en esta proposición (Deus est omnium rerum causa immanens, non vero transiens), es destacable que Macherey traduzca causa "permanente» por immanens y «pasajera» por transiens (Macherey, 1998, p. 149). 
revelan inmensas, no quedando ya dudas de que la Naturaleza no tiene ningún principio o fin trascendente ni para existir ni para obrar. En palabras de Spinoza (2009), "no hay ninguna causa que, extrínseca o intrínsecamente, incite a Dios a obrar, a no ser la perfección misma de su naturaleza." (p. 68). ${ }^{9}$ Una única substancia es la que posee todos los atributos, entre los cuales no existen jerarquías, sino que antes bien, son iguales respecto del orden y conexión de sus modos, a la vez que infinitamente diversos en cuanto a la manera en que se expresan. De modo que la causa inmanente es aquella que no sólo permanece en sí para producir, sino que todo lo que produce permanece en ella, en tanto que son modos en los que ella es determinada.

De modo que para pensar las relaciones modales, hemos de considerar la complejidad que se nos presenta en cuanto al adentro y el afuera en la inmanencia, así como las condiciones externas que determinan cada uno de los modos singulares. Dicho de otra forma: la individuación, en Spinoza, implica pensar la diferencia en la univocidad del monismo, la parte en el todo, el ser "en" otra cosa -la Substancia o Naturaleza- pero sin que esa otra cosa sea radicalmente "otra", es decir trascendente.

En un libro intitulado Spinoza et la politique, el estudioso francés Etienne Balibar (1985) atiende a esta problemática y se propone concebir la ontología de Spinoza como una "ontología de la relación", al modo de una teoría general de la comunicación desde la cual las diferentes formas de la vida imaginaria y racional podrían ser derivadas. Sin embargo, si bien a nivel modal o inter-afectivo se trata sin duda de un plano en el que todas las partes se encuentran vinculadas y trabadas entre sí, no podemos decir lo mismo cuando nos referimos a la substancia. Si atendemos a hilo argumental de las proposiciones de la primera parte de la Ética, vemos que la unicidad de la misma es un punto al que Spinoza arriba luego de una argumentación compleja, en la cual concluye que una substancia es absolutamente infinita y como tal no puede estar limitada por nada. La existencia de "límites" es una condición que incumbe a todos los modos, ${ }^{10}$ y por eso revisten formas determinadas por las que se distinguen en tanto finitos- los unos de los otros. La idea misma de poder entrar en relación con

\footnotetext{
${ }^{9}$ EIP17C1.

${ }^{10}$ También los modos infinitos se circunscriben a ciertos límites, puesto que no son en sí sino que son en la substancia, y no son infinitos absolutamente sino solo en su género. Para mayor precisión, es útil referirse a las primeras definiciones de la Ética, particularmente la V y la VI (Spinoza, 2009).
} 
Individuación y conatus.

Acerca de la existencia inter-afectiva de los modos singulares en la filosofía spinoziana.

otros implica necesariamente la existencia de diferencias, de marcas individuantes, que como tales nos separan y, de esa forma, abren la posibilidad de vincularnos con el mundo sin desintegrarnos en el intento. Justamente, uno de los principales motores que guían la propuesta ética spinoziana es la búsqueda de un remedio al conflicto de los "afectos contrarios", para poder así determinar la fuerza del alma sobre ellos. Es de esta manera que es posible entrar en relación con una cantidad cada vez mayor de modos singulares sin por ello perder la individualidad y la comunicación de movimientos propios. Pero no puede decirse lo mismo cuando nos referimos a la substancia, pues de ella no puede afirmarse ni que posea afecciones contrarias ni que se encuentre con nada fuera de sí. La substancia no solo es potencia y productividad infinita sino que como tal -según reza la Proposición VI de la primera parte de la Ética"una substancia no puede ser producida por otra substancia" (Spinoza, 2009, p. 50). Con ello, Spinoza quiere explicar que en la naturaleza no puede haber dos substancias con el mismo atributo o, lo que es lo mismo, no puede haber dos substancias que tengan algo en común entre sí por lo que puedan ser causa la una de la otra, puesto que todo lo que es, o bien es en sí o bien es en otro, y Spinoza define a la substancia como causa de sí. Justamente, es la primera definición con la que comienza la Ética, dejando asentado que por ello entiende todo aquello cuya esencia implica la existencia o, lo que es lo mismo, aquello cuya naturaleza sólo puede concebirse como existente. En este sentido, puede decirse que para comprender el problema de la individuación en el pensamiento spinoziano es preciso atender a dicha noción de causa sui, puesto que un individuo es justamente lo opuesto, es todo aquello que no puede concebirse por sí solo, que precisa de otros individuos para perseverar en el propio ser y que, por lo tanto, es constantemente causado y explicado por sus vínculos con otros modos singulares.

De modo que, volviendo a la propuesta de Balibar, uno podría preguntarse al respecto si, concebida en toda su radicalidad, una ontología de la relación implicaría ante todo el primado de la relación por sobre la substancia; y, en tal caso ¿no sería ello contradictorio con la noción de substancia spinoziana en términos de causa sui? Vittorio Morfino, quien recoge el planteo de Balibar y lo profundiza aún más, muestra 
que la primera dificultad con la que nos encontramos es el hecho de que en Spinoza está ausente una tematización explícita del problema de las relaciones. (Morfino, 2010). Sin embargo, el autor rescata algunos pasajes e indicaciones al respecto a lo largo de la obra spinoziana. Por un lado, en los Pensamientos metafísicos, Spinoza (2009) escribe que "del hecho de que comparamos unas cosas con otras, van surgiendo ciertas nociones, las cuales, sin embargo, no son, fuera de las cosas mismas, más que modos de pensar" (pp. 300-301), ${ }^{11}$ como es el caso de las nociones de oposición, orden, conveniencia, diversidad, y otras similares. Una idea en el mismo tenor, puede encontrarse asimismo en el Breve Tratado, donde Spinoza (2009) diferencia entre las cosas que están en nuestro entendimiento y las que están en la naturaleza. En el primer caso, dice, "son también una obra exclusivamente nuestra y sirven para entender distintamente. Entre ellas incluimos todas las relaciones que se refieren a cosas distintas, y a las que llamamos entes de razón" (p. 94). ${ }^{12}$ Por otro lado, en la Ética, Morfino (2010) remarca que hay 17 apariciones del término relatio, pero sin embargo no hay definición alguna de la relación en cuanto tal. En la mayor parte de los casos, el término es usado en conexión con verbos como considerari, imaginari, concipi y contemplari. Esto indicaría un estatuto puramente mental de la relación, en la medida en que las cosas pueden ser o no ser pensadas en una relación dada.

Al mismo tiempo, en el Tratado de la Reforma del Entendimiento, encontramos que Spinoza (2009) afirma que de la definición de una cosa deben poder ser deducidas todas las propiedades de ella "considerada en sí sola y no unida a otras" (p. 35). De este modo, parecería que para conocer propiamente algo sería necesario apuntar a la intima essentia y no a las "denominaciones extrínsecas, relaciones o, a lo sumo circunstancias" (pp. 36-37). Podría decirse pues, siguiendo a Morfino (2010), que en el TIE "el concepto de propiedad es ligado a la interioridad de una esencia y el concepto de relación a la exterioridad de la existencia" (p. 45). Sin embargo, Morfino muestra cómo esta idea no continuará de la misma manera en el pensamiento de Spinoza. Pues hay en la Ética una variación respecto del $T I E$, donde el concepto de individuo, de cosa singular, pierde la simplicidad y unidad que de algún modo le confería dicha esencia

\footnotetext{
${ }^{11}$ CM I Cap. V.

${ }^{12} \mathrm{KV}$, I Cap. 10[1].
} 
Individuación y conatus.

Acerca de la existencia inter-afectiva de los modos singulares en la filosofía spinoziana.

íntima, la cual permanecía inmaculada de las relaciones exteriores y de las circunstancias existenciales. Es en la Ética donde claramente se ve el acceso "a la complejidad de una relación proporcionada en la cual la esencia no difiere en ningún modo de la potencia, esto es, de su capacidad de entrar en relación con lo externo" (Morfino, 2010, p. 46). De este modo, la esencia de las cosas reside ahora en el hecho consumado de las relaciones y las circunstancias que han producido la existencia. Aún más,

La esencia de una cosa es concebible sólo post festum, esto es, únicamente a partir del hecho de su existencia o, más precisamente, es a partir de su potencia de actuar que se revela su verdadera interioridad. La barrera entre interior (essentia intima) y exterior (circumstantia), es abatida; la potencia es precisamente la relación regulada de un exterior y de un interior que se constituyen en la relación misma. (Morfino, 2010, p. 47)

De modo que -en respuesta nuevamente a Balibar- podría decirse que las relaciones no pueden preceder a la substancia puesto que de lo contrario ésta no podría explicar causal y esencialmente a aquellas. Pero sí puede concebírselas al modo de un tejido de conexiones singulares que la expresan de cierto y determinado modo, donde el conatus es una fuerza que busca siempre la utilidad recíproca, y donde la comunicación de movimientos es siempre un proceso dinámico inscripto en el tiempo y, como tal, en la imaginación. En palabras de Balibar (2009), puede pensarse en términos de procesos transindividuales de individuación, en los cuales se dan sucesivos órdenes de integración de individuos más complejos.

Ahora bien, a propósito de esta idea de Balibar, creemos que es importante analizar el Lema 7, y hacerlo con cierta cautela, para determinar el alcance real que el mismo tiene en el sistema spinoziano. Allí, luego de afirmar que la noción de individuo es por naturaleza sucesivamente ampliada por composiciones y descomposiciones de segundo y de tercer género, Spinoza (2009) agrega: "Y si continuamos así hasta el infinito, concebimos fácilmente que toda la naturaleza es un solo individuo, cuyas partes -esto es, todos los cuerpos - varían de infinitas maneras, sin cambio alguno del individuo total". (pp. 135-136). ${ }^{13}$ Esto es de gran relevancia, pues la expresión "individuo total" usada por Spinoza, puede tener interpretaciones paradójicas. Por

\footnotetext{
${ }^{13}$ Ell L7SC.
} 
ello, creemos debe ser entendido en un sentido restringido pues, como sabemos, es el individuo el que es divisible en partes y no la substancia, por lo que no podría haber un individuo único que abarcara a todos. Es el individuo el que se compone de elementos separados y no la naturaleza divina y, en consecuencia, es imposible pensar una identificación entre ambos conceptos. La idea de individuo total no refiere a la Naturaleza en tanto que Dios o substancia, sino a la totalidad actual de los modos infinitos, como es por ejemplo la Facies totius universi. ${ }^{14}$ Es posible encontrar algunos elementos que aportan más claridad sobre este problema, en la Carta XII que Spinoza le dedica a Meyer, comúnmente llamada «Carta sobre el infinito». Allí, Spinoza (2007) comparte con su amigo sus meditaciones sobre el problema del infinito, y plantea que las confusiones asociadas al mismo tienen su causa principalmente en que la tradición no supo distinguir entre "tipos" de infinito, entre lo que podemos imaginar y lo que podemos solamente entender pero no imaginar. Pues de lo contrario -escribe Spinoza- "hubiesen comprendido claramente cuál infinito no se puede dividir en partes ni puede tenerlas y, por el contrario, cuál puede tenerlas, sin contradicción. $Y$ más aún, hubiesen comprendido cuál infinito puede concebirse mayor que otro infinito, y cuál no" (pp. 54-55). ${ }^{15}$

Spinoza se refiere a que ciertas cosas son infinitas por su naturaleza y por ello de ningún modo pueden concebirse como finitas, mientras que otras son infinitas solo en virtud de la causa de la que dependen, pero que concebidas abstractamente -es decir por medio de la imaginación- pueden dividirse en partes y considerarse como limitadas; y otras, en fin, infinitas en el sentido de indefinidas porque no pueden igualarse con ningún número (Spinoza da el ejemplo de los círculos no concéntricos), sino que siempre puede concebirse otras más pequeñas o más grandes. ${ }^{16}$

Por otra parte, es interesante pensar cómo esta idea del individuo total puede ser extrapolada a otras expresiones enigmáticas de la Ética. Pensamos, por ejemplo, en la quinta parte de la Ética, en aquella proposición que reza "quien tiene un cuerpo apto para muchas cosas tiene un alma cuya mayor parte es eterna" (Spinoza, 2009, p.

\footnotetext{
${ }^{14}$ La cual, a su vez, remite al atributo extensión.

${ }^{15}$ Ep. Carta XII.

${ }^{16}$ Ep. Carta XII.
} 
Individuación y conatus.

Acerca de la existencia inter-afectiva de los modos singulares en la filosofía spinoziana.

422). ${ }^{17}$ Esta proposición vuelve a poner de manifiesto la relación entre aquello de lo que no puede decirse que tenga partes sino solo en un sentido modal y limitado. Pues ¿cuál es "la parte" en la eternidad? ¿Cómo pensar la demarcación de una fracción de ser en lo que es ilimitado? Una clave para esbozar una respuesta antes de continuar con nuestro siguiente apartado, tal vez esté en la vinculación entre lo que se inscribe en el orden del tiempo y la duración, y lo que Spinoza llama vida libre. Aquella vida en la cual el cuerpo está de tal modo dispuesto que le permite a su entendimiento correr y extender cada vez más los límites de lo que puede abarcar y comprender clara y distintamente. Pierre Macherey se referirá a esto mismo cuando dice que la eternidad incumbe a las expresiones de quien vive una vida libre y activa en el mayor grado posible. Pues es de ese modo como es posible saber orientar los deseos por medio de una comprensión completa de sus condiciones de posibilidad, a través de la conquista de las alegrías concedidas en la formación de ideas adecuadas:

Estas alegrías puras deberán expresar, sin mezcla e irreversiblemente, la expansión de la potencia de ser que se encuentra en cada individuo, a través de la cual se comunica con la totalidad de la naturaleza, y porta así, "en tanto que es en sí» (quantum in se est), como una verdadera «parte total» (pars totalis), su parte del infinito. (Macherey, 1995, p. 378)

Según Macherey (1995), la fórmula "parte total» da cuenta, en su figura de oxímoron, de la idea de una "comunicación" entre la parte y el todo, entre lo finito y lo infinito, constituyéndose como la clave de la concepción spinozista de la liberación. Pues es en el proceso mismo de expandir los límites de lo que somos y de lo que podemos concebir adecuadamente que podemos entender todas las cosas como necesarias y -tal vez por eso mismo- "sentir y experimentar que somos eternos" (Spinoza, 2009, p.409). ${ }^{18}$

\section{La crítica de la individuación y el más allá de la inercia cartesiana}

Dada su naturaleza modal, sabemos que la individuación es siempre para Spinoza un proceso cuantitativo (pues consta de partes) que designa la compleja organización de los atributos. Implica tanto la unidad de una idea -el alma-como la organicidad de

\footnotetext{
${ }^{17}$ EVP39.

18 Al percibirlas tanto por la acción del entendimiento como por las impresiones del cuerpo y la memoria.
} 
partes extensas. La cuestión está en pensar bajo qué relaciones partes cualesquiera pertenecen a un cuerpo dado, pues si la relación falta, entonces no son sus partes; y si subsiste, son sus partes aún si ellas se encuentran en constante cambio. De modo que no son las partes per se las que definen un cuerpo al modo de partes extra partes, sino que lo esencial es la relación bajo las cuales las partes le pertenecen a alguien. Dicha relación, es un grado de potencia, es una fuerza de perseverancia, es la expresión de un conatus. Para Spinoza, todo lo que existe contiene una cierta perfección que es su propia esencia, y que abarca hasta donde se extiende dicha potencia, exponiendo por ello su grado de realidad. ${ }^{19}$ De modo que los elementos de esta tríada de conceptos «potencia-esencia-realidad», que también puede ser pensada como «potenciaperfección-existencia», están vinculados entre sí ontológicamente.

Al mismo tiempo, dicha relación también es una parte, un grado, una fracción de la potencia de Dios, o sea, de la Naturaleza, pero no en cuanto ella es considerada infinita, sino en cuanto puede explicarse de una esencia individual actual, tal como es el caso de los individuos más complejos, i.e. los hombres y mujeres. Pues éstos, como ya dijimos, en tanto que determinaciones de los atributos son una parte de la naturaleza que no puede concebirse por sí sola, sin las demás partes, y por eso mismo son afectados por los demás modos, no siendo más que causa parcial de sus afectos.

Ahora bien, una de las críticas contemporáneas más provechosas sobre cómo se ha concebido el problema de la individuación a lo largo de la tradición filosófica tal vez sea la de Gilbert Simondon. El filósofo francés presenta su propia teoría de la individuación, apoyada en dos observaciones críticas: en primer lugar, el principio de individuación tradicionalmente remitió a un individuo ya totalmente compuesto y constituido, y se limitó a preguntar qué es lo que caracterizaba un ser ya individuado. En segundo lugar, esto tiene como consecuencia el olvido de explicar la operación misma de individuar, predicándose la individuación en todas partes. Se hace de ella coextensiva al ser, olvidando que el principio debe ser auténticamente genético (Simondon hablará por ello en términos de ontogénesis) y no meramente la explicación de un resultado. Falta explicar pues, lo "pre-individual", aquella instancia

\footnotetext{
${ }^{19}$ Es en la primera parte de la Ética, la cual lleva el nombre De Deo, donde se vuelve notorio cómo esta tríada de conceptos se implican entre sí y remiten, a su vez, a la esencia misma de Dios.
} 
Individuación y conatus.

Acerca de la existencia inter-afectiva de los modos singulares en la filosofía spinoziana.

en la que el individuo no es ni todo el ser ni el primero de sus momentos. En términos de Gilles Deleuze (2005), la individuación “debe poder ser situada, determinable con respecto al ser, en un momento que nos hace transitar desde lo pre-individual al individuo" (p. 116). Dicho momento es la condición previa que, para Simondon, consiste en la existencia de un sistema metaestable a partir del cual el ser deviene "de un extremo al otro de sí mismo". El problema con la tradición, es que sólo se interesa en la cuestión de la individuación a partir del individuo. Haciendo esto, se obstina en querer detectar un principio de individuación que solo puede pensarse bajo la forma de un término ya dado. Es así como -para Simondon- el atomismo de Epicuro y Lucrecio plantea el átomo como realidad substancial primera que, gracias al acontecimiento milagroso del clinamen desvía de su trayectoria y se reúne con otros átomos para formar un individuo. Y también, a su manera, el hilemorfismo de la tradición aristotélico-tomista que hace resultar el individuo del encuentro entre una forma y una materia siempre ya individuadas. De modo que tanto los unos como los otros "buscan explicar el resultado de la individuación por un principio de igual naturaleza que dicho resultado, lo que los conduce a pensar el ser bajo la forma del individuo" (Combes, 2017, p. 26). Sin embargo, para Simondon (2009), una filosofía que pretenda realmente llegar a pensar la individuación debe separar lo que la tradición confundió siempre y distinguir el ser en tanto que ser del ser en tanto que individuo.

Ahora bien, ¿qué lugar le cabe a Spinoza en esta tradición? La clave está, claro, en determinar si Spinoza distingue realmente al individuo del ser, esto es, de la substancia única. Simondon (2009) tiene claro cuál lugar le corresponde al filósofo de Ámsterdam, al considerar que Spinoza termina negando la realidad individual puesto que "no comprende propiamente hablando más que un individuo, la naturaleza" (p. 88). Sin embargo, este tipo de críticas dirigidas a Spinoza no son del todo nuevas. Muchas veces se le ha recriminando su panteísmo -generalmente de manera bastante convencional-, no solo como una forma de negar la realidad individual, sino también como negación de la diferencia Creador-criatura. En esta línea se encuentra, mucho antes que la de Simondon, la crítica de Leibniz que, como sabemos, fue relativamente 
contemporáneo a Spinoza y tuvo un asiduo acceso a su Opera Posthuma. ${ }^{20}$ Leibniz le reprocha a Spinoza el no ser capaz de elaborar una teoría del mundo, dado que no podría explicar aquello que es constitutivo del mundo mismo, a saber, estar compuesto de una pluralidad de cosas que se distinguen realmente las unas de las otras. Es iluminador un pasaje de Ipsa Natura en donde Leibniz (1982) afirma que la substancia misma de las cosas consiste en la fuerza de actuar y de padecer, por lo que no pueden producirse en consecuencia cosas durables si el poder divino no puede imprimirles fuerza alguna que permanezca en ellas durante algún tiempo. A continuación -en clara alusión al filósofo holandés- se expresa del modo que sigue:

[Si así no fuera], se seguiría que ninguna substancia creada, ninguna alma continuaría siendo numéricamente la misma, y que por tanto nada podría ser conservado por Dios, y por ello, que todas las cosas sólo serían modificaciones y, por así llamarlas, fantasmas evanescentes y fluidos de la única substancia divina, que es la permanente, y lo que viene a ser igual, que Dios sería la naturaleza misma o substancia de todas las cosas, doctrina de pésima reputación que un escritor sutil pero profano introdujo o renovó recientemente. (Leibniz, 1982, p. 509)

Según esto, las «cosas» comprendidas en tanto que modos de la substancia única spinoziana, no serían más que los elementos de una red universal de relaciones, al seno de la cual un elemento es determinado externamente por una infinidad de otros elementos. Entonces, si una cosa no es más que determinada exteriormente, terminaría por no ser nada en sí misma y no podría, en consecuencia, ser una cosa particular o individual (Bartuschat, 2014, p. 145). Ahora bien, es preciso decir, que las acusaciones que Leibniz realiza no se corresponden completamente con la concepción original de Spinoza, quien define una cosa individual justamente por su conatus o esencia actual y no por la sola conservación de la relación de reposo y movimiento entre partes extra partes.

El problema con esta crítica leibniziana, como muchas de las otras críticas que vinieron después, es que tiende a igualar el pensamiento de Spinoza a la física cartesiana. En consecuencia, creo, es importante despejar algunas de las diferencias

\footnotetext{
${ }^{20}$ Un análisis de la relación entre ambos filósofos puede encontrarse en un artículo de mi autoría, Jabase, A. L. (2020). "Individuación y conatus: puntos de intersección entre Spinoza y Leibniz" en Spinoza Filosofía \& Liberdade, Rio de Janeiro: Editora PUC Rio. EN PRENSA.
} 
Individuación y conatus.

Acerca de la existencia inter-afectiva de los modos singulares en la filosofía spinoziana.

más visibles, principalmente entre las leyes cartesianas del movimiento y el principio del conatus spinoziano. ${ }^{21}$

Como se sabe, en Spinoza el término conatus designa el esfuerzo de perseverar en el propio ser, y constituye una ley que es general para toda la naturaleza y sus infinitos atributos -aunque sea el ser humano quien alcance una dimensión psicológica-racional de ese esfuerzo- y ocupa una función decisiva en lo que respecta a la individuación y la identidad de las cosas singulares. Pascale Guillot (2004) remarca dos momentos determinantes en la construcción del mismo: por un lado, señala la primera ocurrencia explícita del 'conatus' en un pasaje de los Pensamientos Metafísicos, en relación a la fuerza de perseverancia del movimiento en la naturaleza, a partir de la cual Spinoza reformaría el principio de inercia. Allí, Spinoza (2014) enuncia que "el movimiento tiene la fuerza de perseverar en su estado" (p. 305), y que esa fuerza y el movimiento son una y la misma cosa. ${ }^{22}$ Por otro lado, Gillot remarca el establecimiento del conatus como principio de individuación propiamente dicho, expuesto en las primeras proposiciones de la tercera parte de la Ética, y que remiten principalmente a las proposiciones 4 a 9. De este modo, la originalidad propia del concepto de conatus spinoziano en tanto que explicación del movimiento en general, estaría dada por la atribución de la vis perseverandi intrínseca a éste, donde se da una identificación completa entre dicha tendencia intrínseca y la esencia actual de las cosas.

Igualmente, tal como marca André Lecrivain (1986), la definición cartesiana del cuerpo en tanto que diferentes partes puestas en relación, externas las unas a las otras, no es suficiente, en Spinoza, para explicar cuestiones cinéticas más complejas. ${ }^{23}$ Esto lo lleva a concebir una conceptualización renovada de la

\footnotetext{
${ }^{21}$ Un análisis más detallado sobre esto puede encontrarse en otro artículo de mi autoría: Jabase, A. L. (2019). "Del principio de inercia a la ley del conatus", en XIV Coloquio Internacional Spinoza. Valparaíso: Universidad de Valparaíso.

${ }^{22}$ CM PICap6.

${ }^{23}$ Ciertamente, la insuficiencia explicativa de la concepción cartesiana sobre la individuación, en tanto que transporte simultáneo de partes, ha sido más de una vez reconocida. En la segunda parte de los Principios, Descartes (2002) explica que si puede decirse del mismo cuerpo que pasa del estado de condensación al de rarefacción, es porque el cambio afecta solo su figura y no su extensión. Un aumento de su extensión implicaría, en efecto, la añadidura "de una nueva substancia o de un nuevo cuerpo" ( $p$. 76). Esta definición, implica que la identidad de un cuerpo consiste sólo en la conservación de una
} 


\section{Ana Leila Jabase}

esencia del movimiento y sus diversas modalidades. La misma es resumida por el comentador francés en dos aspectos de significancia, uno externo y otro interno:

[Uno] externo, mediante la aplicación de las partes planas (flat) de los cuerpos, unas arriba de las otras, y la presión -en un sentido general- de las cosas circundantes (...); y [otro] interno, mediante la teoría de la esencia singular del conatus, [siendo éste] el grado de complejidad y cohesión característica de cada individuo. (Lecrivain, 1986, p. $39)^{24}$

Esta contraposición evidencia, para Lecrivain, una de las diferencias que pueden encontrarse entre la ley de inercia de Descartes y el principio del conatus spinoziano, entre la interpretación cinética de la individuación en la física mecánica cartesiana y la dinámica interna del conatus, que es una determinación de la infinita productividad de la substancia expresada en cada modo finito. Es por ello que, para Lecrivain (1986), el principio de inercia sería, por decir de algún modo, el reverso y el límite extremo del conatus: "no indica más que las formas extenuadas del conatus, su soporte teórico y abstracto, aquel punto en el que el ser es apenas distinguible de la nada" (p. 48). Aquí, el 'quantum in se est' se muestra en su mínimo, por debajo de lo cual ya no es nada. En este sentido, los cuerpos más simples serían pura exterioridad y el conatus terminaría desapareciendo al convertirse simple y abstractamente en la ley de inercia.

\section{El individuo en el entramado de las imágenes}

Ahora bien, a propósito de la aplicación de las partes extensas unas sobre otras, es preciso referirnos al concepto spinoziano de imagen para comprender mejor qué es el individuo, dada la estrecha vinculación entre la imaginación y la corporalidad. Spinoza (2009) explica qué entiende por «imaginación» y qué por «imágenes» en la Proposición XVII de la segunda parte de la Ética, donde define a las «imágenes» de las cosas como "las afecciones del cuerpo humano cuyas ideas nos representan los cuerpos exteriores como si nos estuvieran presentes, aunque no reproduzcan las

\footnotetext{
misma cantidad de materia, no es más que una parte de ella; y no contiene ninguna fórmula que singularice la relación que las partes tienen entre sí, de manera tal que dicha relación pueda subsistir y el individuo conservar su identidad, a pesar del cambio o renovación de las partes.

${ }^{24}$ Todas las traducciones del inglés son de mi autoría.
} 
Individuación y conatus.

Acerca de la existencia inter-afectiva de los modos singulares en la filosofía spinoziana.

figuras de las cosas" (p. 141). ${ }^{25}$ A continuación agrega que puede decirse que el alma «imagina» cuando considera los cuerpos de esta manera. De modo que las imágenes no son otra cosa que «corporis affectionem», o sea una afección del cuerpo.

Ahora bien ¿̇en qué consiste este proceso esencialmente corporal de la adquisición de imágenes? Sabemos que, para Spinoza (2009), el cuerpo humano se compone de múltiples individuos de diversa naturaleza, cada uno de los cuales son a su vez muy compuestos, y es "como si estos lo regenerasen continuamente" (p. 137). ${ }^{26}$ Al mismo tiempo, son afectados de muchísimas maneras por los cuerpos exteriores, padeciendo sus afecciones. Respecto de estas últimas, Spinoza (2009) dice que pueden ocasionar diversas mutaciones en el cuerpo, "sin dejar por ello de retener las impresiones o huellas de los objetos, y por consiguiente, las imágenes mismas de las cosas" (p. 194). ${ }^{27}$ Spinoza (2009) tiene un término específico para referirse a estas impresiones o huellas de los objetos que es vestigia, introducido por primera vez en la Ética en el quinto postulado de la segunda parte. Allí dice: "Cuando una parte fluida del cuerpo humano es determinada por un cuerpo externo a chocar frecuentemente con otra parte blanda, altera la superficie de ésta y le imprime una suerte de vestigios del cuerpo externo que la impulsa" (p. 137). ${ }^{28}$

Al menos dos elementos son importantes rescatar en esta cita. Primero, que la frecuencia de la afección es determinante a la hora de imprimirse el vestigio en el cuerpo; y segundo, que los mismos dependen del modo en que se encuentra dispuesta la superficie de ese determinado cuerpo, puesto que a ella obedece la fluidez, blandura o dureza de sus partes. Esto se encuentra en relación con las leyes ópticas de la reflexión de la luz que Spinoza introducirá en su explicación de los cuerpos, bajo la forma de axioma:

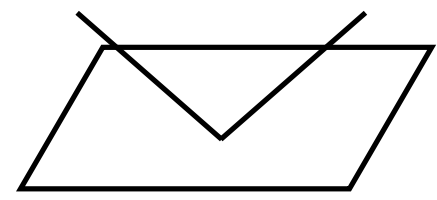

Fig. 1

Cuando un cuerpo en movimiento choca contra otro en reposo al que no puede mover, es reflejado de modo que sigue moviéndose, y el ángulo que forma con la superficie del cuerpo en reposo, contra el que chocó, la línea del movimiento de

\footnotetext{
${ }^{25}$ Ell P17Sc.

${ }^{26}$ Ell Post.4.

${ }^{27}$ Elll Post2.

${ }^{28}$ Ell Post.5.
} 
reflexión, será igual al ángulo que forma la línea de movimiento de incidencia con esa superficie. (Spinoza, 2009, p. 132) ${ }^{29}$

De ello se sigue que toda vez que un cuerpo externo se aplica sobre otro provocando una afección o una impresión, efectúa una desviación en el plano de las partes fluidas, provocando que choquen repetidamente contra las blandas, es decir, que cambian en algún grado su superficie. Y si se modifica la superficie de un cuerpo, en igual medida "aquellas [las partes fluidas] son reflejadas de manera distinta a como solían serlo antes" (Spinoza, 2009, p. 132). ${ }^{30}$ De modo que, acorde al axioma arriba anunciado, las partes fluidas de un cuerpo humano que son afectadas por otro, se reflejan en un ángulo de igual incidencia. Es decir, tal como puede verse en la Fig.1, el ángulo que forma el cuerpo originador del movimiento de choque con el cuerpo en reposo que fue chocado (Spinoza dirá la línea del movimiento de reflexión), "será igual al ángulo que forma la línea del movimiento de incidencia con esa superficie" (Spinoza, 2009, p. 140). ${ }^{31}$ Esta es la forma en la que un cuerpo produce una serie de imágenes que, cuando se vuelven frecuentes dejan los trazos o vestigios del objeto original. Y no solo eso, sino que esa misma corporis affectionem "resonará" en el alma al formarse una idea de la misma, tal como se sigue del principio de unión psicofísica spinoziana. De ese modo, el alma considerará el cuerpo exterior como presente, "y ello tantas veces cuantas las partes fluidas del cuerpo humano encuentren, en su espontaneo movimiento, las mismas superficies" (Spinoza, 2009, p. 140).

A partir de esto, podría decirse que toda acción está unida a una imagen de las cosas: son ellas las que le permiten al cuerpo "estar dispuesto para hacer esto o aquello" (Spinoza, 2009, p. 230). ${ }^{32}$ En palabras de Lorenzo Vinciguerra (2005), "el cuerpo se encuentra encadenado a sus imágenes. Depende de ellas" (p. 194). Y puesto que el cuerpo en cuanto tal es afección, no existe en la naturaleza cuerpo alguno si no es en tanto que modificado, y es impensable sin las múltiples relaciones que tiene con el ambiente que lo rodea. A su vez, en cuanto afección "existe siempre como afección de una afección, es decir como una práctica o conjunto de prácticas" (Vinciguerra,

\footnotetext{
${ }^{29}$ EII A2.

${ }^{30}$ EII P17Dem.

${ }^{31}$ EII P17Dem.

${ }^{32}$ EIII P32.
} 
Individuación y conatus.

Acerca de la existencia inter-afectiva de los modos singulares en la filosofía spinoziana.

2012, p. 16). ${ }^{33}$ Sin embargo, no se trata de concebir la distinción entre lo duro, blando o fluido como una propiedad en sí misma de los cuerpos. Se trata del modo en que se traban o desunen los cuerpos, de la expresión relativa de "las diferencias trazables en la naturaleza" (Vinciguerra, 2012, p. 26). Es decir, el trazo o vestigio tiene un carácter esencialmente relacional, que le impide ser concebido como una realidad absoluta, cerrada en sí misma. Así, por «blandura» ha de entenderse la capacidad de un cuerpo de ser revestido de trazos, de vestigios; la «dureza», por su parte, ha de ser definida como la capacidad menor del cuerpo -o también la resistencia más grande- para ser trazado por otros. La «fluidez», por último, consiste en la mayor capacidad para recibir los trazos de los otros cuerpos, al mismo tiempo que la capacidad menor para conservarlos. Lo cual conlleva que se transmute inmediatamente en otro cuerpo. En ese sentido, la blandura puede ser pensada como la capacidad media de todos los cuerpos en general, en la medida en que todos se constituyen por su trazabilidad. En suma: los vestigios no son meros hechos accidentales, sino que son lo que necesariamente resulta de la actividad cinética general del atributo extensión.

Ahora bien, es preciso recordar aquí lo que Spinoza escribe, antes de definir la dureza, la blandura y la fluidez, en el axioma III donde dice que un individuo, o sea un cuerpo compuesto, "reviste" una determinada figura que le "sobreviene" con mayor o menor facilidad según sean mayores o menores las superficies por medio de las cuales las partes del mismo se aplican unas contra otras. En esa misma medida, la figura que le sobreviene revestir puede mutar en otra esencialmente distinta. Sin embargo, en el lema IV, Spinoza vuelve a referirse a los cuerpos compuestos, afirmando que si un individuo compuesto de varios cuerpos se separa de algunos de ellos a la vez que otros de la misma naturaleza ocupan el lugar de aquellos, ese individuo conservará su naturaleza tal como era antes, sin cambio alguno de su forma. De modo que los conceptos de "forma» y "figura», así como aquello que un cuerpo «reviste» o le "sobreviene», se encuentran mutuamente imbricados y se vuelven esenciales para determinar en qué consiste la esencia de un cuerpo y sus afecciones. A la vez, es también necesario retener la noción de "superficie», puesto que es en ella donde se

\footnotetext{
${ }^{33}$ Todas las traducciones del italiano son de mi autoría.
} 


\section{Ana Leila Jabase}

marca el límite entre lo interno y lo externo a un cuerpo. Es allí que se decide su unión o separación: tal como Spinoza lo explica, es la modificación debida a la presión de los cuerpos circundantes, la que causa que el cuerpo revista cierta y determinada forma. ${ }^{34}$

Para finalizar este apartado, tal vez sea útil recordar el devenir del poeta español al que Spinoza (2009) alude en la Ética, pues su historia puede aportarnos un último elemento para comprender la naturaleza interafectiva de la imaginación y de los cuerpos. Este poeta, producto de una enfermedad, había experimentado tales cambios que le provocaron el olvido de las piezas teatrales que había escrito, así como el olvido de su propia historia de vida (Spinoza, 2009). ${ }^{35}$ A partir de ello podemos preguntarnos qué sucede si la forma de un determinado cuerpo no logra continuar componiéndose con aquello que lo circunda, o si los trazos y vestigios de las figuras que reviste traspasan el límite de su cuerpo. Sin duda, la respuesta se deduce de lo que hemos dicho hasta aquí: ocurre la mutación de su forma. Pero es preciso destacar que la mutación de la forma es, de hecho, la otra cara de la propia muerte, o sea de que las partes dejen de comunicarse, permitiendo la transformación en otra cosa distinta. Ocurre a veces -dice Spinoza- que un hombre experimenta tales cambios que difícilmente se dirá de él que es el mismo.

De modo que con esta historia Spinoza intenta mostrar hasta qué punto pueden ciertos afectos perjudicar o beneficiar a un cuerpo, y hasta qué punto la memoria y el cúmulo de imágenes y vestigios del mundo circundante, constituyen la esencia actual del mismo. Y si se pierden, si se desvanecen en la infinidad de las determinaciones del atributo extensión, se llevan con ella la identidad de ese hombre. Es en ese sentido que, de la muerte del cuerpo, Spinoza dice que sobreviene cuando sus partes quedan dispuestas de tal manera que alteran la relación de reposo y movimiento que hay entre ellas, y a continuación agrega:

Pues no me atrevo a negar que el cuerpo humano, aun conservando la circulación sanguínea y otras cosas que se piensan ser señales de vida, pueda, pese a ello, trocar su

\footnotetext{
${ }^{34}$ Para mayor claridad en esta relación forma-figura, Vinciguerra (2012) apela al término latino que Spinoza utiliza en este contexto: se trata del verbo induere (introducido en el axioma III), que quiere decir «vestirse de». La figura, por tanto, opera al modo de un revestimiento o ropaje de la forma; es simultáneamente una relación que es a la vez interna a la forma y externa a la figura de los otros cuerpos; "es la forma modificada" (p. 36).

${ }^{35}$ EIV P39Sc.
} 
Individuación y conatus.

Acerca de la existencia inter-afectiva de los modos singulares en la filosofía spinoziana.

naturaleza por otra enteramente distinta. En efecto: ninguna razón me impele a afirmar que el cuerpo no muere más que cuando es ya cadáver. (Spinoza, 2009, p. 332) ${ }^{36}$

Queda claro pues, que para Spinoza la vida de un cuerpo, de un organismo, es algo más que la circulación sanguínea o el aire que respiran sus pulmones. La muerte le puede advenir igualmente, pese a que así también el latido de su corazón continúe su movimiento. Esto es así en la medida en que tal movimiento ya no lo hará en comunicación con las otras partes de su cuerpo que lo constituían. En algún momento, ese cuerpo se enfermó, la proporción de movimiento quedó desbocada, desregulada, y provocó la digresión de las mismas. Y por más de que el cuerpo de aquel poeta tenga más o menos la misma apariencia estética, ya no es el mismo: han cambiado sus hábitos, su manera de dejar trazos en los otros.

\section{La vida común del conatus}

Podría decirse que el aspecto más común y visible de la vida afectiva es aquel que se muestra en la fluctuación del ánimo. Allí, las personas se encuentran llevadas de un lado a otro, movidas de muchas maneras por las causas exteriores. En palabras del escritor de la Ética, ocurre que los hombres -y mujeres- "semejantes a las olas del mar agitadas por vientos contrarios, nos balanceamos, ignorantes de nuestro destino y de nuestro futuro acontecer" (Spinoza, 2009, pp. 260-261). ${ }^{37}$ Para entender esto, tal vez pueda servirnos la expresión «passionibus obnoxius», una locución frecuente en la pluma de Spinoza tal como lo ha hecho notar Morfino, la cual tiene una capacidad sintetizadora sobre la naturaleza de la vida afectiva. Literalmente significa "subyugados" o "sujetos" a las pasiones; pero también tiene la doble valencia de aquello que perjudica y aquello que invade o se apodera. En algunas versiones, como en la edición italiana del Tratado Político, se la ha traducido incluso como "atravesado por las pasiones" (Morfino, 2010, p. 50). Esta expresión, más allá de las discusiones exegéticas, creemos es interesante, en la medida en que da cuenta de la naturaleza relacional y vinculante de los afectos. Al mismo tiempo, al balancearnos atravesados por vientos contrarios que dejan su huella en nuestro cuerpo, también somos

\footnotetext{
${ }^{36}$ EIV P39SC.

${ }^{37}$ EIII P59SC.
} 
constituidos por ese ser-atravesados, donde nuestro afecto más primario no es otro que el mismo deseo. El cual implica siempre un esfuerzo por aumentar la potencia y la capacidad de continuar deseando y desplegando la fuerza del cuerpo y del alma. A partir de allí, es posible comprender que la vía que nos procura una mayor utilidad y contento es aquella que se encamina en dirección a la búsqueda de lo común, de la composición con los demás modos de la naturaleza; pues son los afectos comunes los que aumentan la fuerza del conatus con la que no sólo nos conservamos sino con la que también maximizamos nuestra virtud. $Y$ es justamente esta aptitud afectiva, que es siempre diversa en cada determinación modal de la substancia, la que nos identifica como siendo un cuerpo u otro. Esto puede verse en el escolio de la Ell13, donde Spinoza refiere al principio general de diferenciación entre los cuerpos. Allí sostiene que para distinguir un alma de otra, en cuanto ella es idea, hemos de referirnos al cuerpo que es su objeto. Asimismo, sabemos que para Spinoza un cuerpo es un individuo, una relación de partes que presentan una cierta velocidad de movimiento, y "cuanto más apto es un cuerpo que los demás para obrar o padecer muchas cosas a la vez, tanto más apta es su alma que las demás para percibir muchas cosas a la vez" ( $p$. $129) ;^{38}$ y cuanto más dependen las acciones de un cuerpo de ese cuerpo solo, tanto más apta es su alma para entender distintamente.

De este modo, los cuerpos se separan de los demás cuerpos y se aventajan en la medida de sus aptitudes para obrar o afectar. En este contexto, pensar en términos de «aptitud para obrar o afectar», no significa otra cosa que lo que los distingue no solo es el grado de potencia que los constituye, sino también la pluralidad simultánea (plura simul) de las mismas. Para ello, es preciso entrar en relación con lo externo en orden a poder diversificar la propia trama afectiva, es decir buscar la composición modal, la vida común del conatus. Spinoza (2009) tiene un término para referirse a ello, que es la «amistad». La cual implica el afecto activo más decisivo de la ética: la fortaleza (fortitudo), en sus ambas formas, firmeza y la generosidad. De la primera, en un sentido amplio, podría decirse que radica en ejercitar la fuerza tanto del propio cuerpo

\footnotetext{
38 Ell P13Sc. Allí Spinoza (2009) también agrega que para determinar qué es lo que separa al alma humana de las demás y en qué las aventaja, nos es necesario conocer la naturaleza de su objeto, esto es, del cuerpo humano.
} 
Individuación y conatus.

Acerca de la existencia inter-afectiva de los modos singulares en la filosofía spinoziana.

como del alma que es su idea, para ser uno la causa adecuada de sus afectos en la mayor medida que sea posible y en el mayor grado que el mundo y los cuerpos circundantes nos lo permitan. De la segunda, implica la búsqueda por establecer una relación con los otros, bajo la forma de la amistad. Es sobre la base de estos afectos que Spinoza muestra un vínculo fundamental entre las relaciones inter-afectivas y el amor intelectual a Dios, entre el ser libre y vivir en el Estado. Pues el hombre que se guía por la razón y se esfuerza por vivir libremente, "desea [también] sujetarse a las reglas de vida y utilidad comunes y, por consiguiente, desea vivir según la legislación común del Estado" (Spinoza, 2009, pp. 365-366); donde todos los hombres pueden potenciar su existencia mediante la asistencia de unos hacia otros. De esta manera, pueden componerse en un gran individuo, aumentando así su propio derecho natural, el cual apenas puede ser concebido sino es allí donde los hombres poseen derechos comunes. Por tanto, "cuantos más sean los que se así se unen, más derecho tienen todos juntos" (Spinoza, 2004, p. 99), ${ }^{39}$ permitiendo a su vez que todos puedan ser guiados "como por una sola mente" (Spinoza, 2004, p. 99). ${ }^{40}$

François Zourabichvili (2014) muestra esto con lucidez, cuando plantea que lo que define a un individuo es el equilibrio entre cantidades variables, con un determinado margen de transgresión. En otras palabras, un individuo o cuerpo cualquiera consiste en "una cantidad variable que oscila en torno de una constante, y que no puede sobrepasar cierta amplitud sin poner fin a la oscilación y no poder volver a la constante" (p. 51). La constante define pues dicho estado de equilibrio, mientras que los límites determinan la amplitud máxima del desequilibrio que un cuerpo puede soportar. Y si extendemos este análisis a la noción de cuerpo político vemos cómo también la paz o concordia es también la norma de equilibrio que lo sostiene. Es así como la verdadera paz del Estado, en tanto que finalidad interna o inmanente del cuerpo político -sostiene Zourabichvili-, solo es posible si éste puede dotarse de las instituciones que aseguren la paz civil o sea la conservación del cuerpo. De modo que volvemos a encontrar la misma problemática:

\footnotetext{
${ }^{39}$ TP Cap. II §15.

40 TP Cap. II §16.
} 
La constante (concordia) no es un valor absoluto, contrariamente a lo que creen los partidarios de la monarquía absoluta que sacrificarían gustosamente la libertad, fuente de querellas y desordenes relativos, al orden público. Spinoza muestra por un lado que eso es instaurar una falsa paz, por otro lado que la verdadera paz tiene como condición la tolerancia de las diferencias individuales. (Zourabichvili, 2014, p. 53)

Es así como la cuestión de la "conveniencia", así como de la mutua utilidad, se vuelve el elemento central para entender toda relación compositiva en los cuerpos. Pues dada la distinción esencial de los individuos, la conveniencia solo puede ejercerse en función de lo que éstos tienen en común (la cual nunca puede ser total o completa), como puede ser una afectividad común, una aspiración común o una determinada serie de hábitos, de prácticas sociales. A propósito de ello, es útil recordar el análisis que Spinoza (1997) hace de los ritos en el Estado hebraico ${ }^{41}$, mostrando cómo una formación político-social es un individuo que se sostiene por sus prácticas, por sus ideas-pasiones que lo atraviesan, y que traban y anudan entre sí sus partes o individuos más simples. La idea de conveniencia aplicada a un cuerpo político consiste, pues, en un grado de utilidad común suficientemente consistente como para que los individuos puedan juntarse y mantener la unión durante algún tiempo. O bien, como dice Zourabichvili (2014), "cuando las diferencias no son lo suficientemente importantes como para que los renunciamientos mutuos a través de los cuales los individuos llegan a convenirse no los disuadan de unirse por significar un renunciamiento a ellos mismos" (p. 53).

Así pues, la búsqueda de esta utilidad común, que también es cautela y prudencia, es también la búsqueda de la comunidad posible, que incumbe directamente al desafío de cómo relacionarse con uno mismo y con los otros. Finalmente, de lo que se trata es de comprender la relación entre una parte de la naturaleza que no puede concebirse por sí sola, y la serie infinita de individuos y causas externas, de ese individuo total, que no es más que la faz misma del universo que nos sobrepasa infinitamente en potencia.

${ }^{41}$ TTP Cap. 5. 
Individuación y conatus.

Acerca de la existencia inter-afectiva de los modos singulares en la filosofía spinoziana.

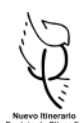

\section{Bibliografía}

- Balibar, E. (2009). Spinoza de la individualidad a la transindividualidad. Córdoba: Encuentro Grupo Editor.

(1985). Spinoza et la politique. Paris: Presses Universitaires de France.

- Bartuschat, W. (2014). Modes ou monades? Leibniz critique Spinoza. En Moreau, P.-

F., Andrault, R. \& Lærke, M. (Eds.), Spinoza et Leibniz Rencontres, controverses, réceptions (pp. 145-157). Paris: PUPS.

- Bayle, P. (2010). Diccionario histórico y crítico. (Bahr, F. Trad.). Buenos Aires: Cuenco del Plata.

- Combes, M. (2017). Simondon. Una filosofía de lo transindividual. Buenos Aires: Cactus.

- Deleuze, G. (2005). Gilbert Simondon: el individuo y su génesis físico-biológica. En La isla desierta y otros textos. Textos y entrevistas 1953-1974 (pp. 115-119). Valencia: Pretextos.

- Descartes, R. (2002). Principios de la filosofía. Barcelona: Alianza.

- Freudenthal, J. (1899). Die Lebensgeschichte Spinozas. Leipzig: Quellenschriften, Urkunden und nichtamtlichen Nachrichten (29).

- Dominguez, A. (1995). (Comp.) Biografías de Spinoza. Madrid: Alianza.

- Guillot, P. (2004). Le conatus entre principe d'inerte et principe d'individuation. Sur l'origine mécanique d'un concept de l'ontologie spinoziste. Dix-septième siècle PUF, $222,51-73$.

- Jabase, A. L. (2020). Individuación y conatus: puntos de intersección entre Spinoza y Leibniz. En Spinoza Filosofía \& Liberdade. Rio de Janeiro: Editora PUC Rio (En prensa). (2019). Del principio de inercia a la ley del conatus. En Cápona

González, D. \& Rojas Castro, B. (Comps.), XIV Coloquio Internacional Spinoza. Repensar la potencia revolucionaria de la modernidad (pp. 118-128). Valparaíso: Autoedición.

- Jaquet, C. (2005). Les expressions de la puissance d'agir chez Spinoza. Paris: Publications de la Sorbonne.

- -------- (2008). Spinoza o la Prudencia. Buenos Aires: Tinta Limón.

- Lacan, J. (2008). "Función y campo de la palabra y del lenguaje en psicoanálisis". 
En Escritos 1 (pp. 227-310). Buenos Aires: Siglo XXI.

- Lagrée, J. (1994). Spinoza «athée \& épicurien». Archives de philosophie 57(3), 541558.

- Lecrivain, A. (1986). Spinoza and carteasian mechanics. En Marjorie Grene \& Debra Nails (Eds.), Spinoza and the Sciences (pp. 15-60). Dordrecht: Reidel Publishing Company.

- Leibniz, G. W. (1982). Sobre la naturaleza misma, es decir, sobre la fuerza ínsita en las acciones de las criaturas para confirmar y aclarar la dinámica del autor. En Escritos Filosóficos. Buenos Aires: Editorial Charcas.

- Macherey, P. (1998). Introduction à l'Ethique de Spinoza. La première partie. La nature des choses. Paris: PUF.

(1995). Introduction à l'Ethique de Spinoza. La troisième partie. La vie affective Paris: PUF.

- Marx, K. (1994). Tesis sobre Feuerbach. En La cuestión judía (y otros escritos). Madrid: Planeta-DeAgostini.

- Meschonnic, H. (2015). Spinoza poema de pensamiento. Buenos Aires: co-ed. Tinta Limón \& Cactus.

- Morfino, V. (2010). Relación y contingencia, Córdoba: Encuentro Grupo Editor.

- Simondon, G. (2009). La individuación a la luz de las nociones de forma y de información. Buenos Aires: Cactus \& La Cebra.

- Spinoza, B. (2009). Ética, demostrada según el orden geométrico. Madrid: Alianza Editorial.

(2009). Tratado de la reforma del entendimiento. Principios de la filosofía de Descartes. Pensamientos metafísicos. Madrid: Alianza Editorial.

-

-

- ----------- (2004). Tratado Político. Madrid: Alianza Editorial. (1997). Tratado teológico-político. Madrid: Ediciones Atalaya.

- Strauss, L. (1973). Persecution and the Art of Writing. Connecticut: Greenwood Press Westport. 
Individuación y conatus.

Acerca de la existencia inter-afectiva de los modos singulares en la filosofía spinoziana.

- Vinciguerra, L. (2012). La semiotica di Spinoza. Pisa: Edizioni ETS.

- Vinciguerra, L. (2005). Spinoza et le signe. La genèse de l'imagination. Paris: Vrin.

- Zac, S. (1995). Spinoza et l'interprétation de l'Écriture. Paris: PUF.

- Zourabichvili, F. (2014). Spinoza, una física del pensamiento. Buenos Aires: Cactus. 